use for understanding cells that do not communicate using electrical impulses. It is this view that has perpetuated our comparative ignorance about glia.

Moreover, the exclusion of glia from the BRAIN Initiative underscores a more general problem with the project: the assumption that enough measuring of enough neurons will in itself uncover 'emergent' properties and, ultimately, cures for diseases ${ }^{1,4}$. Rather than simply materializing from measurements of "every spike from every neuron"1,4, better understanding and new treatments will require hypothesis-directed research. The 302 neurons and 7,000 connections that make up the nervous system of the roundworm Caenorhabditis elegans were mapped in the 1970s and 80s. More than two decades later, little is understood about how the worm's nervous system produces complex behaviours.

In any major mapping expedition, the first priority should be to survey the uncharted regions. Our understanding of one half of the brain (the part comprised of astrocytes, oligodendrocytes and microglia) lags a century behind our knowledge of neurons. I believe that answers to questions about the brain and public support for a large-scale study are more likely to come from expanding the search into this unknown territory. As a first step, tools such as optogenetic methods and mathematical models are needed to assess the number, distribution and properties of different kinds of glial cell in different brain regions, and to identify how glia communicate with each other and with neurons, and what developmental and physiological factors affect this. This exploration into the 'other brain' must be done together with the proposed studies of neurons. It cannot be achieved as a by-product of them.

R. Douglas Fields is chief of the Nervous System Development and Plasticity Section at the US National Institutes of Health in Bethesda, Maryland. e-mail:fieldsd@mail.nih.gov

1. Alivisatos, A. P. et al. Science 339, 1284-1285 (2013)

2. Kettenmann, H. \& Ransom, B. R. (eds) Neuroglia 3rd edn (Oxford Univ. Press, 2013).

3. Fields, R. D. The Other Brain (Simon \& Schuster, 2009).

4. Alivisatos, A. P. et al. Neuron 74, 970-974 (2012).

5. Schafer, D. P. et al. Neuron 74, 691-705 (2012).

6. Fields, R. D. et al. The Neuroscientist (in the press).

7. Wake, H. Lee, P. R. \& Fields, R. D. Science $\mathbf{3 3 3}$, 1647-1651 (2011)

8. Zatorre, R., Fields, R. D. \& Johansen-Berg, H. Nature Neurosci. 15, 528-536 (2012).

9. Han, X. et al. Cell Stem Cell 12, 342-353 (2013).

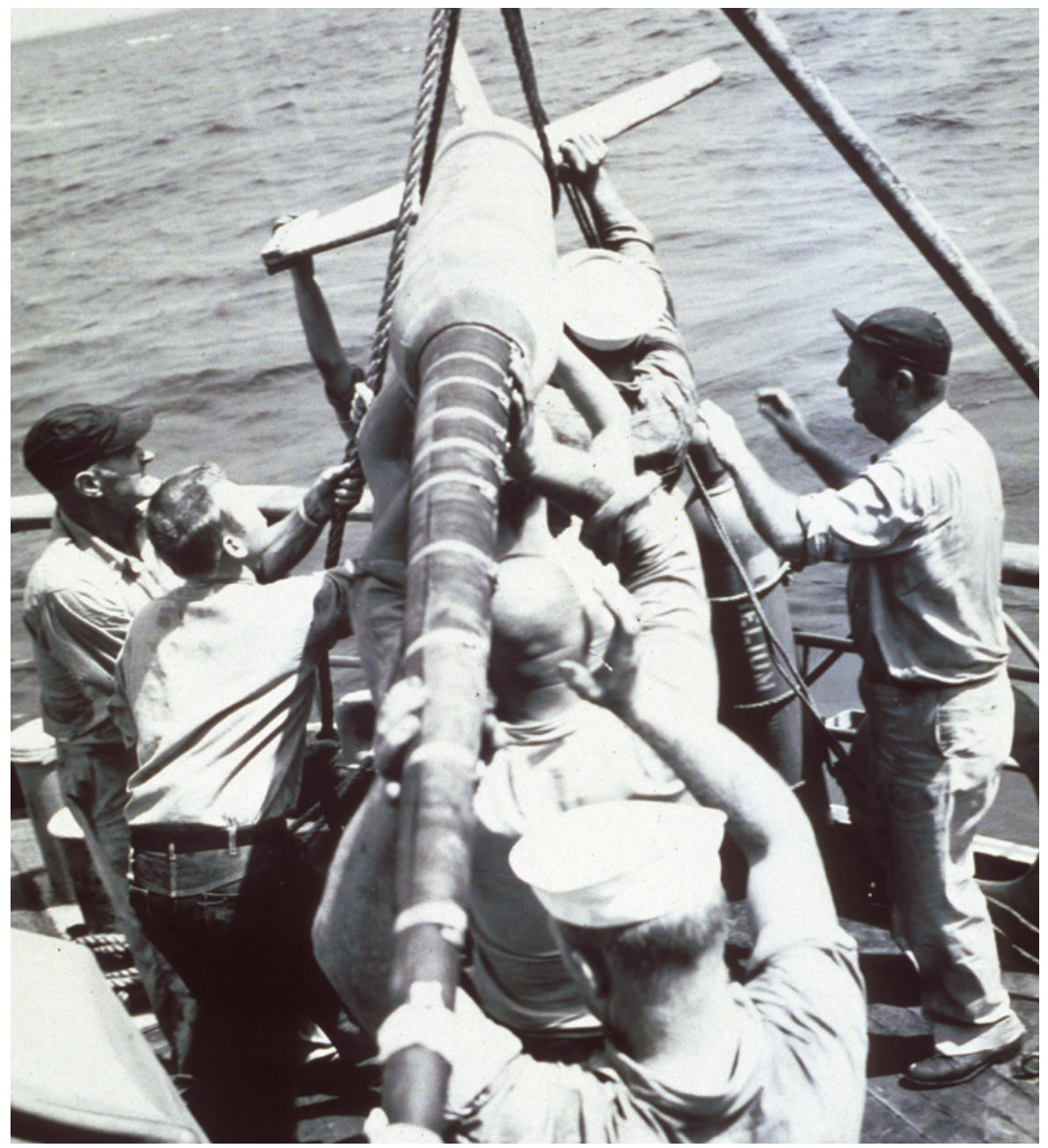

The US research vessel Explorer towed a magnetometer to map fields over the sea floor in 1960.

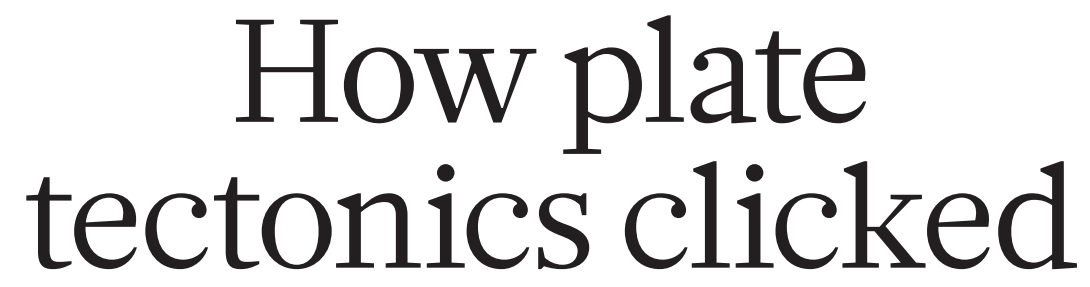

Fifty years after a paper linked sea-floor magnetic stripes with continental drift, Naomi Oreskes explains its legacy as a lesson in achieving scientific consensus.

$\mathrm{B}$ $y$ the time German geophysicist Alfred Wegener proposed continental drift in 1912, palaeontologists had long accepted that past connections between now-separate lands explained the spread of similar fossils and rock layers across them. Geologists, too, knew of slabs of Alpine rock that had been displaced hundreds of kilometres during mountain building.

But the arguments for continental motions did not gel until the 1960 s, when a drastic expansion of geophysical research, driven by the cold war, produced evidence that reopened and eventually settled the debate.

One influential study was published ${ }^{1}$ in Nature 50 years ago this week. British geologists Frederick Vine and Drummond Matthews interpreted stripes of alternating magnetic-field polarity in ocean bedrock as evidence of a spreading sea floor that pushed continents apart. Acceptance that large crustal motions were a reality soon followed, culminating in the theory of plate tectonics.

In its slow convergence of ideas and evidence, the history of plate tectonics holds lessons for today's debates about 


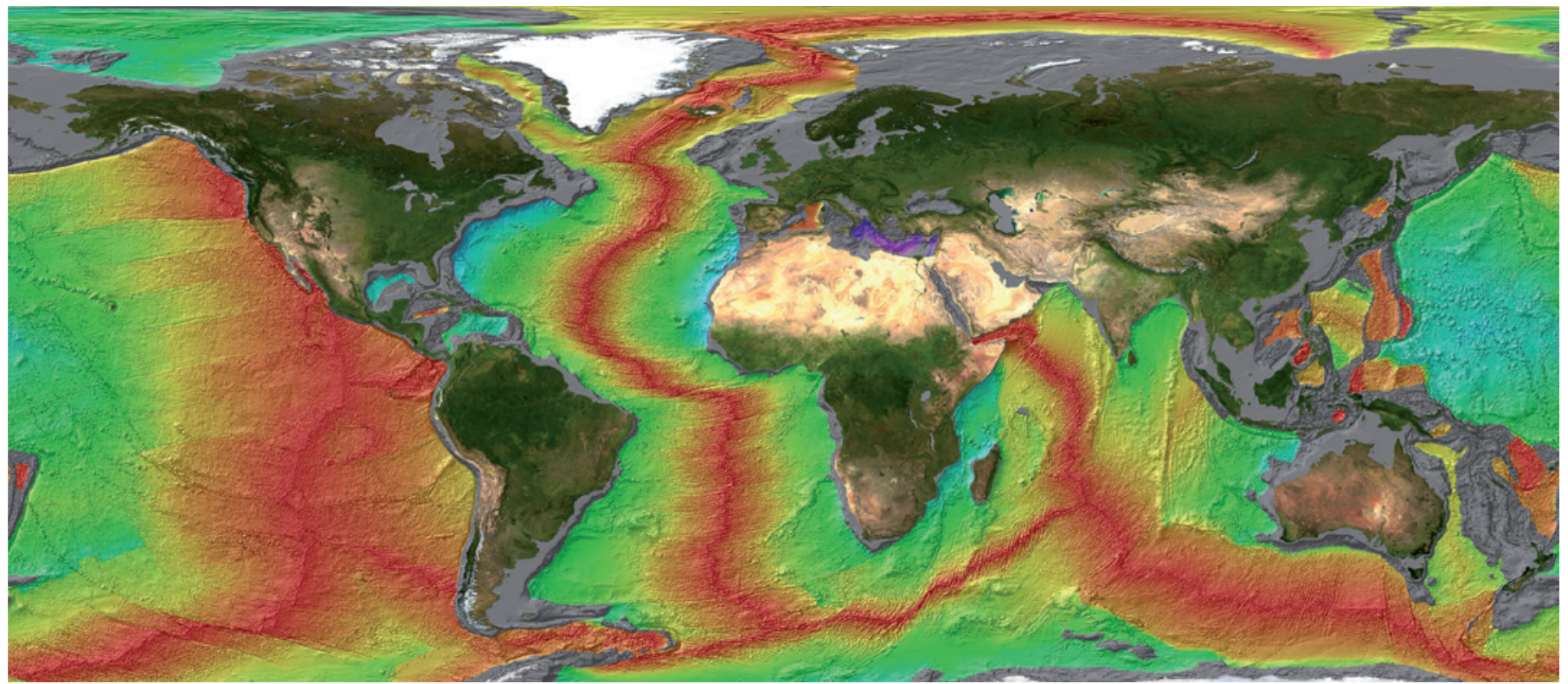

The age of ocean rocks increases (red to purple, 0-280 million years) with distance from ridges, where crust is formed, revealing the spread of the sea floor.

> human-induced climate change. Although science is always evolving, and our attention is drawn to controversy at the research frontier, it is the stable core of 'consensus' knowledge that provides the best basis for decision-making.

\section{MANTLE CONVECTION}

Wegener stands out because his solution was close to the one that we now accept, and because our individualist culture encourages us to look for heroes to credit and discrete events to celebrate. But he was not alone in trying to explain commonalities in fossils and rock strata. In the English-speaking world, two of the most important players in developing theories of continental-scale crustal mobility were South African field geologist Alexander du Toit and British geochronologist Arthur Holmes.

Du Toit articulated the case in his aptly named 1937 book Our Wandering Continents (Oliver and Boyd). He acted as a clearing house for geologists around the globe, who sent him maps, rocks and fossils. Holmes, working with the Irish geochemist John Joly, suggested that crustal motion was driven by radioactivity and the heat that it emanates, advocating mantle convection as a means of dissipating radiogenic heat and driving continental drift ${ }^{2}$. Holmes's 1944 textbook Principles of Physical Geology (Thomas Nelson \& Sons) was an introduction to the subject for many students.

The discussion was joined by Dutch geodesist Felix Vening Meinesz, who worked in the 1930s in the Indonesian archipelago and, with US geologists Harry Hess and Maurice Ewing, in the Caribbean. Meinesz found that Earth's gravitational field was weaker than normal above some of the ocean's deepest regions, which he explained in terms of the buckling of low-density crust into the mantle, dragged down by descending convection currents, and he discussed these ideas with Hess.

During the Second World War, Hess found himself in the US Navy, fighting in the Pacific theatre. He did not return immediately to tectonics after the war, but others did, including several British geophysicists led by P. M. S. Blackett and Keith Runcorn. In an effort to understand "More than the origins of Earth's twodozen magnetic field, they scientists discovered that magdid the key netic minerals pointed work that in different directions created the at different times in theory of plate geological history, as tectonics." if the positions of the poles had changed.

Hess was drawn back to the topic after realizing that these 'apparent polar-wandering paths' could be explained by the movements of the continents.

\section{OCEAN SPREADING}

Hess suggested that rising mantle-convection cells would drive apart the ocean floor above them, increasing the separation of continents to either side. The idea, which his colleague Robert Dietz christened 'sea-floor spreading'3 ${ }^{3}$, explained the old geological observations and the new geophysical ones, but it did not gain immediate traction. That would take further geomagnetic information.

Blackett, a socialist who opposed nuclear proliferation, turned to geomagnetism after the war to distance himself from military work ${ }^{4}$. But military concerns - particularly the demands of submarine warfare in the atomic age - drove geophysical exploration of the ocean floor, leading to the discovery in the late 1950s of sea-floor magnetic stripes.

The stripes were a surprise. In the report of the discovery, oceanographers Ronald Mason and Arthur Raff admitted to being at a loss for an explanation. Others were less stymied. Vine and Matthews, as well as Canadian geophysicist Lawrence Morley, independently had the same idea. If the sea floor was spreading, then magnetic stripes would be expected: rock formed at mid-ocean ridges would take on Earth's magnetic field, the polarity alternating as the field periodically reversed.

It was one thing to say that the oceans were widening, another to link it to global crustal motion. More than two dozen scientists, including women such as Tanya Atwater and Marie Tharp, did the key work that created the theory of plate tectonics as we know it - explaining continental drift, volcanism, seismicity and heat flow around the globe ${ }^{5}$.

In 1965, Canadian geologist Tuzo Wilson proposed a type of 'transform' fault to accommodate the spreading sea floor around midocean ridges, which was confirmed by US seismologist Lynn Sykes. Other seismologists demonstrated that in deep-ocean trenches, slabs of crust were indeed being driven into the mantle, and geophysicists worked out how these crustal 'plates' move and relate to the features of continental geology.

Vine and Matthews' work is part of a larger story of the growth of Earth science in the twentieth century, made possible by improved technology and greater governmental support after the Second World War. Nearly all seismic and marine geophysical data at the time were collected with military backing, in part because of their cold-war security significance.

This era marked a change in the character of modern science. Research today is expensive and largely government-funded; almost 
all major scientific accomplishments are the collective achievement of large teams. This reality - more prosaic than the hagiography of lonely genius - reminds us that although great individuals are worthy of recognition, the strength and power of science lies in the collective effort and judgement of the scientific community.

\section{CONSENSUS MATTERS}

In recent months, several of my colleagues in climate science have asked me whether the story of plate tectonics holds lessons for their field in responding to those who disparage the scientific evidence of anthropogenic climate change. I believe that it does.

Many critics of climate science argue that expert agreement is irrelevant. Science, they claim, advances through bold individuals such as Wegener or Galileo Galilei overturning the status quo. But, contrary to the mythology, even Isaac Newton, Charles Darwin and Albert Einstein worked within scientific communities, and saw their work accepted. In glorifying the lone genius, climate-change dissenters tap into a rich cultural vein, but they miss what consensus in science really is and why it matters.

Consensus emerges as scientific knowledge matures and stabilizes. With some notable exceptions, scientists do not consciously try to achieve consensus. They work to develop plausible hypotheses and collect pertinent data, which are debated at conferences, at workshops and in peer-reviewed literature. If experts judge the evidence to be sufficient, and its explanation coherent, they may consider the matter settled. If not, they keep working. History enables us to judge whether scientific claims are still in flux and likely to change, or are stable, and provide a reasonable basis for action.

And maturity takes time. Scientific work, compared with industry, government or business, has no deadline. Perhaps for this reason, when Wegener died in 1930, according to

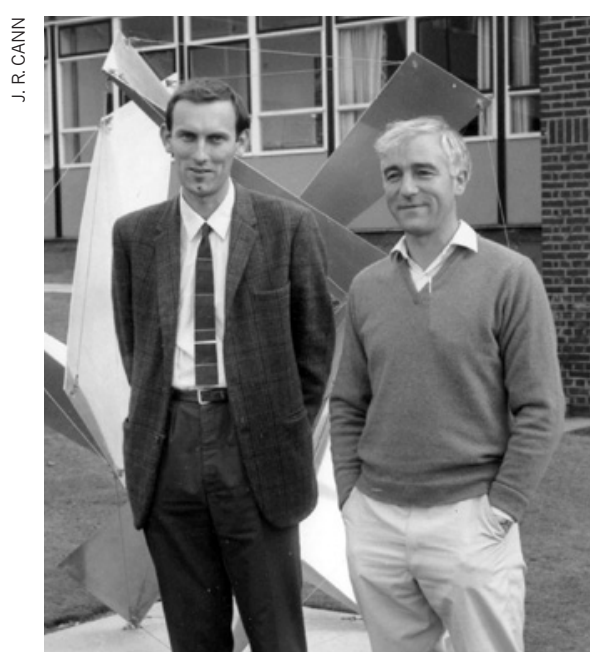

Frederick Vine and Drummond Matthews (1970). his biographers he was confident that other scientists would one day work out how the continents moved, and that this mechanism would be along the lines of his proposal as indeed it was. Du Toit and Holmes were similarly convinced.

The equanimity of these men speaks to their confidence in science as a system. They perceived what historian-philosopher Thomas Kuhn articulated in The Structure of Scientific Revolutions (University of Chicago Press, 1962): that science is a community affair and that knowledge emerges as the community as a whole accepts it. A debate comes to a close once scientists are persuaded that a phenomenon is real and that they have settled on the right explanation. Further discussion is not productive unless new evidence emerges, as it did for continental drift.

Anthropogenic climate change has the consensus of researchers. Political leaders who deny the human role in climate change should be compared with the hierarchy of the Catholic church, who dismissed Galileo's arguments for heliocentrism for fear of their social implications. But what of scientists who in good faith reject the mainstream view?

Harold Jeffreys is an intriguing example. An eminent professor of astronomy at the University of Cambridge, UK, Jeffreys rejected continental drift in the 1920s and plate tectonics in the 1970s. He believed that the solid Earth was too rigid to permit mantle convection and crustal motion. His view had a strong mathematical basis, but it remained unchanged, even as evidence to the contrary mounted.

If society had faced a major decision in the 1970s that hinged on whether or not continents moved, it would have been foolish to heed Jeffreys and to ignore the larger consensus, backed by half a century of research. As an early advocate of an immature theory, Wegener was different. There were substantial differences of opinion about crustal mobility among scientists in the 1920s. By the 1970s, work such as Vine and Matthews' study had brought consensus.

Fifty years on, history has not vindicated Jeffreys, and it seems unlikely that it will vindicate those who reject the overwhelming evidence of anthropogenic climate change.

Naomi Oreskes is professor of the history of science at Harvard University in Cambridge, Massachusetts.

e-mail:oreskes@fas.harvard.edu

1. Vine, F. J. \& Matthews, D. H. Nature $\mathbf{1 9 9}$ 947-949 (1963).

2. Oreskes, N. The Rejection of Continental Drift: Theory and Method in American Earth Science (Oxford Univ. Press, 1999).

3. Dietz, R. S. Nature 190, 854-857 (1961).

4. Nye, M. J. Blackett: Physics, War, and Politics in the Twentieth Century (Harvard Univ. Press, 2004).

5. Oreskes, N. (ed.) Plate Tectonics: An Insider's History of the Modern Theory of the Earth (Westview Press, 2001). 